Review Article

\title{
Wrong Region and Bottleneck Analysis of the Self-healing System in Smart Grid
}

\author{
Liu Yong-chun, Lin Yu-zi, Zhang Wen-sheng \\ Department of Mechanical and Electrical Engineering, Xiamen University Tan Kah Kee College, Zhangzhou, China \\ Email address: \\ lyc782@126.com (Liu Yong-chun),yzlin@xujc.com (Lin Yu-zi),wensheng@xujc.com (Zhang Wen-sheng)
}

\section{To cite this article:}

Liu Yong-chun, Lin Yu-zi, Zhang Wen-sheng. Wrong Region and Bottleneck Analysis of the Self-healing System in Smart Grid. American Journal of Electrical Power and Energy Systems. Vol. 5, No. 5, 2016, pp. 51-58. doi: 10.11648/j.epes.20160505.12

Received: September 12, 2016; Accepted: September 23, 2016; Published: October 15, 2016

\begin{abstract}
The research on the self-healing system in smart grid is a worldwide research topic, and it has very important significance for the safe and stable operation of the power grid. The research topic was proposed by America Electric Power Science Research Institute since the beginning of the century, over the past ten years, the research has still no substantive progress. Therefore, this paper, with a large number of literature data and examples as the basis, by means of contrast, analyzes the existing problems and misunderstandings in the study of the topic, reveals the bottleneck problems encountered in the process of the research, and specifies the research of the self-healing system to quickly restore power as the main objective, will be the recovery control of the self-healing as the focus of the self-healing system research, so as to point out the direction for the further research of the subject, in order to make the majority of researchers in the future research avoid detours, early results.
\end{abstract}

Keywords: Smart Grid, Self-healing System, Connotation, Denotation, Bottleneck Analysis, Electrical Accident, Self-healing Recovery Control, Expert System

\section{Introduction}

The research on self-healing system in smart grid is a very attractive field, also is one of the important frontier technology in the field of electrical engineering in the world today. The new concept of "smart grid" and "self-healing system" was proposed by America Electrical Power Science Research Institute since the beginning of the century, soon got the multinational colleges and universities, research institutes and professionals wide attention and favor. Many countries have spent a lot of manpower, material and financial resources to carry out a series of research, also published a large number of research literature. But, more than ten years have passed, for the research on "self-healing system" is still hovering in the initial concept, and no substantive progress has been made. One of the reasons is worth people to think about. If the research of the self-healing system can get a breakthrough progress, will bring a major technological leap for the future development of electrical engineering.

\section{Introduction of the Concept of Smart Grid and Self-healing Systems}

Before and after 1996, the United States has a series of more than a large range of power outages [1-2], has caused serious economic losses. For the August 10, 1996 blackout, accident, some experts believe, if it can tap out $0.4 \%$ of the load from the system, and continues to 30 minutes, blackout accidents can be avoided in the western United States [3]. This suggests that the national power grid in the United States, there are some weak links, it also shows that the fast recovery of power system is more important after the occurrence of electrical accident.

Although the occurrence of electrical accidents is just a point, however, the impact is often a face. $\mathrm{n}$ order to prevent and reduce the rate of a series of power outages and catastrophic accidents, In 2000 by the United States at the university of Washington, university of Arizona, Iowa state university and Virginia tech to launch set up a association of advanced electric power technology (APT), first put forward 
with a wide range, intelligent, adaptive protection and control system of the new concept of the future power grid, which is "Strategic Power Infrastructure Defense system Strategic Power Infrastructure Defense (SPID) System", from the height of the national defense strategy study and resolve weak technical problems in power Infrastructure, based on extensive analysis the basis, the power grid can provide critical information, a large number of real-time data, the system of weak can be quickly assessed, especially has the ability of self-healing and adaptive recovery in time [3]. This is the concept of "smart grid" initial form.

Since then, Electric Power Study Institute in United States (EPRI) described the definition of smart grid is "self-healing, security, integrated, collaborative, prediction, optimization and interaction" concepts such as collection, this definition reflects the three important requirements for power grid construction in United States: reliability requirements (self-healing, safety, forecasting), economy and efficiency requirements (optimization, collaborative, interactive), technical support request (integrated) [4]. In this definition, for the first time the Electric Power Study Institute puts forward the concept of grid "self-healing" and emphasized the self-healing power grid is the focus of the power grid construction in United States. After that, the European Union, China and other countries have also proposed a similar concept. Although various countries have different description of smart grid, however, the recognition of the "self-healing" system has reached a broad consensus [4].

\section{Research Situation and Existing Problems of Self-healing System in Power Grid}

"Self-healing" was originally a concept in the biomedical field. Encyclopedic scholar Xian Zhang found in the study of medical theory, self-healing is human and other living organisms in a foreign invasion, or under the condition of the harm such as mutation in the inner life, maintain the individual living a life phenomenon, has the spontaneity, and other significant characteristics of the dependency and role of continuous, self-healing process based on its intrinsic self-healing system, with self-healing force expression, to exclude the violation of external or internal to the human body and other living organisms, and the repair has been damage, to achieve the continuation of life [5]. You can see that the self-healing system is an instinct of life. In recent years, in the study of the smart grid, the ideas of the self-healing system is also used in the automatic control of power systems.

Since the concept of smart grid and self-healing system is proposed, many countries have spent a lot of manpower, material and financial resources to carry out a series of research, has also made some of the results of the stage. The distribution automation advanced (ADA) phase of the advanced distribution automation technology has been developed in the United States; Japan after three stages of development, development and promotion of remote workstation to dispatching automation system, enter the control mode of the workstation; Singapore's self-healing control technology to the distribution network management system of data acquisition, monitoring and asset management to achieve full coverage [6]. China has made some achievements in the research of intelligent power grid selfhealing control technology, realize the intelligent meter reading [7],created intelligent substation, strengthen the research and application of distributed and renewable energy resources [8], made clear the important role of real time data information in the self-healing system [9], the key technologies of intelligent power distribution network self-healing control system are studied [10].

Many scholars have put forward the model and structure of self-healing control system and different analysis algorithms in theory [11-17]. The author to "smart grid of the self-healing system research" as keywords from the browser "CNKI" refer to the during the period of March 2000 to 2015 16 years a total of more than 2440 articles academic literature, from collection, selected 42 papers. Table 1 is the statistical analysis of the attribution and the results of the authors.

Table 1. The distribution table of the results number.

\begin{tabular}{llllll}
\hline Master, PhD & University Scholars & Business expert (reporter) & Model research & Method study & Practical application research \\
\hline 17 & 12 & $11(2)$ & 13 & 23 & 6 \\
\hline
\end{tabular}

From table 1 can be seen, the authors mainly concentrated in three groups, masters and $\mathrm{PhD}$, University academics and business experts, the characteristics of achievements, mainly for model research, research methods and practical application of the three aspects. From the quantitative point of view, in the 42 papers, master, Bo graduate and university scholars research results accounted for 29 , enterprise experts accounted for 11 of the research results ( 2 reporters). From the research content, there are 13 models of the research, there are 23 methods of research, the practical application of research only 6 .

The author has further selected 10 articles with some influence from 42 literatures, according to the serial number, the first author, title, the core contents of the literature were summarized in Table 2 , respectively. 
Table 2. Self-healing system has academic value of the research results list.

\begin{tabular}{|c|c|c|c|}
\hline $\begin{array}{l}\text { Serial } \\
\text { number }\end{array}$ & Make a writer & Title & Core content \\
\hline 1 & Guo Zhizhong & $\begin{array}{l}\text { Power grid self-healing control } \\
\text { scheme }\end{array}$ & $\begin{array}{l}\text { The structure of "2-3-6" power grid self-healing control system and its related } \\
\text { problems are discussed [18]. }\end{array}$ \\
\hline 2 & Wan Qiulan & $\begin{array}{l}\text { Theoretical research on the } \\
\text { realization of self-healing in } \\
\text { large power grid } \\
\text { 《Automation of electric power } \\
\text { system》 }\end{array}$ & $\begin{array}{l}\text { Describes the application of complex network theory to research the power grid; } \\
\text { application measurement unit (PMU) based on trajectory study of power system } \\
\text { stability point of view and the overall research ideas. The emphasis is placed on the } \\
\text { search method of restoration of self-healing grid strategy and grid [4]. }\end{array}$ \\
\hline 3 & Yu Kun & $\begin{array}{l}\text { Research on self-healing } \\
\text { control of urban power grid } \\
\text { based on hierarchical control } \\
\text { theory }\end{array}$ & $\begin{array}{l}\text { Study on hierarchical control theory and intelligent groups system theory } \\
\text { establishment of city power grid self-healing control system structure and control } \\
\text { model based on and approach to design self-healing control and running in the urban } \\
\text { power grid vulnerable assessment based on the implementation of a reasonable } \\
\text { control scheme [19]. }\end{array}$ \\
\hline 4 & Jia Dongli & $\begin{array}{l}\text { Research on the framework of } \\
\text { self-healing control technology } \\
\text { in intelligent distribution } \\
\text { network }\end{array}$ & $\begin{array}{l}\text { This paper analyzes the structure and technology of self-healing control system of } \\
\text { intelligent power distribution network, including the basic layer, supporting layer and } \\
\text { application layer, and expounds the structure and function of each layer [17]. }\end{array}$ \\
\hline 5 & Zheng Xiaofan & $\begin{array}{l}\text { Self-healing control of smart } \\
\text { grid based on power immune } \\
\text { system }\end{array}$ & $\begin{array}{l}\text { The power of the immune system self regulating function of a biological immune } \\
\text { system for self-healing control. And introduces the composition and functions of the } \\
\text { system [20]. }\end{array}$ \\
\hline 6 & Dong Xuzhu & $\begin{array}{l}\text { Self-healing control system of } \\
\text { intelligent power distribution } \\
\text { network }\end{array}$ & $\begin{array}{l}\text { Introduces the centralized, decentralized, centralized and decentralized self-healing } \\
\text { control the advantages and disadvantages of the system architecture, basic conditions } \\
\text { and key technology, analyzes the problems and challenges faced by the technology } \\
\text { research and application of intelligent distribution network self-healing control [21]. }\end{array}$ \\
\hline 7 & $\begin{array}{l}\text { Zhang } \\
\text { Mingguang }\end{array}$ & $\begin{array}{l}\text { Self-healing control of multi } \\
\text { agent layered intelligent } \\
\text { distribution network }\end{array}$ & $\begin{array}{l}\text { Stratification was carried out according to the function of the distribution network, } \\
\text { multi-agent technology and grid operation state combination, according to the } \\
\text { different operation state implementation of different control strategies, and make full } \\
\text { use of the autonomy of the multi agent technology and cooperation, for smart } \\
\text { distribution grid self-healing control to provide a basis of theory and method [22]. }\end{array}$ \\
\hline 8 & Qin Hongxia & $\begin{array}{l}\text { Research and design of } \\
\text { intelligent power distribution } \\
\text { network self-healing control } \\
\text { system }\end{array}$ & $\begin{array}{l}\text { The function of intelligent power distribution network self-healing control system is } \\
\text { analyzed, and the architecture, interface and related indexes of intelligent power } \\
\text { distribution network self-healing control system are designed [10]. }\end{array}$ \\
\hline 9 & Hong Tao & $\begin{array}{l}\text { Status and development of } \\
\text { intelligent power distribution } \\
\text { network fault recovery }\end{array}$ & $\begin{array}{l}\text { The fault recovery of distribution network with multiple faults and distributed } \\
\text { generation is analyzed systematically, the research direction of fault restoration in } \\
\text { distribution network is discussed, and the problems in the research of fault recovery } \\
\text { are analyzed [23]. }\end{array}$ \\
\hline 10 & Yuan Bo & $\begin{array}{l}\text { Self-healing control and key } \\
\text { technology of intelligent power } \\
\text { distribution network }\end{array}$ & $\begin{array}{l}\text { The self-healing control "three layer seven unit structure, combined with the } \\
\text { characteristics of intelligent distribution network with distributed power, makes up } \\
\text { the defect of self-healing control did not fully consider the characteristics of } \\
\text { intelligent distribution network [24]. }\end{array}$ \\
\hline
\end{tabular}

The core contents of the literature in Table 2 are analyzed, among them, [1], [2], [4], [6], [7] and [8]so on, mainly based on model research. From different perspectives, the authors put forward the structure and control model of self-healing control system, "2-3-6" self-healing system structure model, three layer structure model of "basic layer, support layer and application layer", self-healing control system model of multi agent distributed power distribution network, self-healing control of the "seven tier three unit" architecture model, etc.

In addition, some authors put forward different research methods of self-healing control.

The author believes that in the research literature, author Yu Kun puts forward the theory of hierarchical control in the literature [19] and Dong Xuzhu's analysis on the advantages and disadvantages of centralized, decentralized, centralized decentralized self-healing control system in the literature [21] are more significant for the study of "smart grid self-healing system".

The author also reviewed the research situation abroad "smart grid self-healing system", not many valuable documents.

The following figure is the distribution map drawn by the author according to the number of research literature.

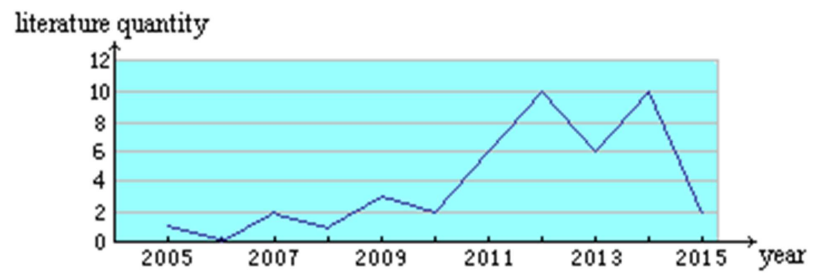

Figure 1. The distribution map of the results number published every year.

Can be seen from the figure, from 2000 to 201010 years, there are a small amount of research results published each year, from 2011 to 20144 years, the number of published results is more than 10 times the previous 3 years, there has been a substantial increase, there are two small climax; after 2015, published literature has been significantly reduced, and 
so far, there have been no signs of a marked achievement.

At present, although China has attached great importance to the research of self-healing control technology, Its pilot work from the State Grid to the southern power grid has a certain coverage [25], however, due to the relevant systems, equipment, technology is not mature, the network infrastructure is weak, the communication means is not complete and other reasons, intelligent power distribution network self-healing control effect is very little [6]. Even from the perspective of the world's research results, the research on the self-healing system has not made substantial progress.

Give a simple example, more than a decade ago, the self-healing system immediately entered the research phase; also more than a decade ago, the mobile phone in the public began to popularize, but also just analog signals. Today, ten years later, mobile phones have entered into the new era of digitization, networking and 4G, anytime, anywhere, can let the user network aware world anecdote; and the research of the self-healing system is still in the exploration stage of "feeling the stones across the river". In today's world, a variety of technologies with each passing day, and the selfhealing system is out of step with the pace of the times, this is worth thinking about.

Self-healing systems research progress is slow, may explain a problem, that is research on self-healing system appeared wrong direction, to say the least is unknown direction, so that the study into a serious mistake.

\section{Analysis of the Self-healing System Error}

In biology, self-healing system there are two remarkable characteristics, the one is a preventive, the second is healing. People with the help of the biomedical field self-healing system to study the problem of the safe and stable operation of the smart grid is a pioneering, has very good prospects. But, you must understand the essence difference between the biological self-healing systems with the self-healing smart grid existed. The blogical self-healing system with the self-healing smart grid system is completely different in both intension and extension. The connotation of the former is just a living organisms, the connotation of which is by running a special function of inanimate device cluster composed of rigid body. Such as generator, transformer and motor and the complexity of the grid. Extension of the former is an independent complete individual, but the extension of the latter is a large, scattered, can also be a stretching of the power supply network.

In addition, on the characteristics of it, the biology of self-healing system has the characteristics of spontaneity, the dependence and sustainability, is determined by the biological genetic instinct. And this feature in the smart grid self-healing system is simply does not have, is also impossible to have. One of the most simple example, if the human body skin abrasions, even without the help of external drug treatment, under the action of self-healing systems in the body, after a few days can heal naturally. However, suppose that a electrical equipment insulation abrasion, if not in time to stop to external repair processing, then, under the action of the rated voltage, I'm afraid it will soon be breakdown.

If you don't tell the difference between the two different areas of the self-healing systems, emphasis on preventive and curative blindly, naturally on the strong smart grid infrastructure to do a large number of articles, even willing to invest a lot of manpower and material resources and financial resources. Of course, strengthen the application of the distributed energy and renewable energy, is very beneficial to improve the natural environment, reduce pollution, is desirable. However, when there is serious short circuit accident on supply network, simply by distributed power grid to provide electricity to supplement of power grid, I'm afraid it is not enough, at best is but a drop in the ocean. Besides, to strengthen infrastructure has its limits, could not achieve one hundred percent, table redundancy, otherwise the costs and benefits will be upside down, more do more harm than good. Even so, the accident situation, how to quickly implement electrical equipment redundancy switching is a fairly complex technical problems, the problem is not solved, more redundant equipment is without letup.

So, if to jump from the system study of misunderstanding, will fall into a bottomless vortex, or lost exports into a large within the labyrinth.

\section{Difficulties and Bottlenecks Analysis of the Self-healing System}

Dr. Yu Kun from Zhejiang University In his dissertation points out: "the scholars study self-healing control methods are consistent, the self-healing control is reflected in two aspects, namely the advance active prevention and control, and afterwards the self-healing recovery control [19]. " This is what people in the study of self-healing system to reach a consensus, also explains the smart grid in the study of the self-healing system including two aspects, one is the study of the prevention and control, the second is self-healing recovery control study. The former focuses on the prediction analysis of any abnormal situation and to take measures in advance. The latter is then focused on when the electrical accident of power grid operation mode has been damaged how quickly,accurately reconstruct, that is how to quickly and accurately recovery of power supply for the non fault area,the non fault lines, the non fault equipments by the impact of power outages electrical accident, so that the blackout accident losses to a minimum extent, simply speaking is how to study the spot treatment for the electrical accident. It can be said that the study on two kinds of control are very meaningful, also with difficulty. However, in comparison, the self-healing recovery control study will no doubt be more difficult, have more significance.

Whether it's a supply network or a substation, its 
connotation has not repair and sudden, and extension are dilated and uncertainty. So by many internal and external interference factors, so the electrical accident is almost a kind of inevitable, this is one side of the grid vulnerability.

According to a senior power scheduling expert introduction, he worked in a large state-owned enterprise for more than 20 years, experienced the process a lot of electrical accidents, each treatment is thrilling, always on tenterhooks, is racing against time. Due to the southern Leizhou peninsula area, annual the summer two season, the grid will always suffer the multi-faceted and typhoons, thunderstorms attacks. He remembers one time the power grid of the $110 \mathrm{kV}$ substation 4 40MVA transformer in the super typhoon raging in three successive sudden power outage, factory more than 20 sets of chemical production equipment suddenly cutting off water and electricity, safety in production has been seriously threatened. If it is not in the shortest period of time to restore power, a slight mistake may cause a series of chemical plant fire and explosion and personal casualty accident. Crisis time, with the power dispatching on duty personnel on the spot. From 8:00 in the morning until 2:00 $\mathrm{pm}$, as soon as the system was restored to power, the whole typhoon stopped, once again restored after the whole stopped, was this constant recovery, constantly stopped, and the days of fighting, over and over again. After more than 6 hours of continuous intense command processing, the typhoon weakened, and finally to the whole plant power grid system to restore the normal power supply, ensure that the plant chemical production device does not have the slightest secondary accident. The processing of a pile of electrical accidents that can achieve fast and accurate processing electrical accidents is safe, that is effective.

The research of self-healing system in smart grid has brought hope to the automatic treatment of electrical accident. If the self-healing system can be successful, no matter what kind of electrical accident occurred in the system, can be in a few seconds, the longest is just a few minutes will be able to return to normal system. The speed and efficiency of accident treatment will be far beyond reach the power dispatch personnel, and the economic and social benefits will be considerable. Just now, from power system to production enterprise, the power grid management departments at all levels to deal with the electrical accident is still based on the power dispatch of the spot command, rarely seen through the self-healing control to achieve automatic processing of electrical accident case. The author sees, in the research results of many scholars, is still much virtual, the real thing is less, operational technical measures are less, some of the research on the control of self-healing is just a word, can go deep into the substantive stage of study is rare. Literature [26] introduced the January 15, 2014 national network Zhejiang Electric Power Corporation Organization experts on the smart distribution network self-healing control research and application project for acceptance of the situation, the project is undertaken by China EPRI 2012 national network of Zhejiang Province Electric Power Company of science and technology projects, mainly has conducted the research on the theory of intelligent distribution network self-healing control, risk assessment, fault diagnosis and safety early warning technology. However, in this paper, the research on self-healing recovery control technology has not been mentioned. Literature [10] that can be said that the latest achievements in the research of smart grid and self-healing system which were recently published in 2014, in this paper, the function, the whole frame, the related interface and the related technical indexes of the self-healing control system of intelligent power distribution network are designed. The key technologies of intelligent power distribution network selfhealing control system are studied, including the "hierarchical coordination of self-healing control technology, distribution fast simulation and modeling technology, distribution network self-healing control online intelligent analysis and decision-making technology, intelligent distribution network under extreme conditions critical load security technology and large area outage restoration technology, intelligent distribution network fault isolation and reconfiguration technology" five key technology. Especially the mentioned according to the design development of intelligent distribution network self-healing control system has successfully run in the demonstration project site, and can meet the actual demand of intelligent distribution network self-healing control, to achieve the desired design goals. But, the author sees, in this paper, what is the actual demand for self-healing control of the demonstration project, and what is the realization of the self-healing control technology is not given a specific description. That is to say, the study of "self-healing recovery control technology" in this paper is also not mentioned.

In fact, since the concept of "self-healing" system was put forward, more than ten years have passed, the research has still in the exploratory stage, enough to see the complexity and difficulty of the study. It also shows that the research of "self-healing control technology" is the most important research content in the process of self-healing system, is undoubtedly an important bottleneck. If this bottleneck problem is not resolved, to achieve the function of the self-healing system in intelligent power grid is probably very far away.

\section{Study Direction of the Self-healing System}

The research of self-healing system is the core content of smart grid. From the study of many scholars can be seen, everyone on the prevention and control of the self-healing system do sufficient article. Although "preventive control" is one of the important research contents in the intelligent power grid, but it is not the focus of the self-healing system, emphasis should be placed on the study of "self-healing control technology", which is the direction of the research of the self-healing system. The former can only be icing on the cake, and the latter is only called timely assistance. Say again, preventive control most of the solution is some abnormal 
problems in power network, such as high voltage or low problem, the problem of low power factor and fire arc suppression coil compensation, transformer oil temperature is too high problem, and the trend of distribution problems. Although these problems may also lead to electrical accidents, but in the stable operation of the power grid, all of these problems can be controlled and adjusted in advance. Such as on-line transformer on load voltage, capacitor reactive power automatic compensation, fire arc suppression coil automatic tracking shifting and transformer load shunt, these measures are already quite mature in the existing power grid technology, and the application is also very extensive. As for the power supply of the distributed power supply, it is also very limited. Therefore, the focus of the research of the self-healing system should be the self-healing control technology.

Here, the author might as well use a hospital doing a metaphor, if a hospital can only some simple prescription drugs to the patient at ordinary times, and cannot do surgery for severe patients in time, so, at best, the hospital can be a health clinic, is hardly a hospital. In the same way, only the control and prevention, and no the self-healing recovery control of power grid system also can not be called the self-healing system in the smart grid.

The process of the self-healing recovery control of power grid also can saying is the process of network reconfiguration of distribution network. Dr. Yu Kun from Zhejiang University in his dissertation points out: "the distribution network reconfiguration is a mathematical problems of nonlinear combinatorial optimization, to solve the problem algorithm can be roughly classified into three categories: traditional mathematical optimization algorithm, heuristic algorithm and artificial intelligence algorithm. " and In the artificial intelligence algorithm there are simulated annealing, neural network, genetic algorithms, evolutionary algorithms and expert system etc. [19]. " From the height of the mathematical to analysis study the self-healing recovery control problem indeed has certain scientific and systemic, but the difficulty is very big.

Luo Jinshan of Huazhong University of Science and Technology and other scholars put forward, "The power network accident is caused by the complex sequence of multiple concurrent faults, if the chain model of system accident can be established before the accident, analysis of the complex sequence of system accidents, will be conducive to the monitoring of the system accident [27]." In this paper, a stochastic Petri net SPN (Petri Nets Stochasitic) is proposed to establish the fault chain model of power system, the power system accident is regarded as an accident chain which is caused by many factors, and fast dynamic search algorithm is used to solve the accident chain, so as to find out the accident point and so on, that is, through the accident treatment plan to form a typical accident treatment program. It should be said that there is not a few scholars of this formulation.

In simple terms, this idea seems reasonable, but it is almost impossible to carry out. Because of the type of fault in power grid is numberless as the sand, both single accident, and system of the accident, the more difficult is every accident is different. If you want to build accident chain model that may need to be conceived many types of accidents, also do not know to how much time it takes to complete? Say again, electrical accidents are accidental and unexpected, as a power grid, may occur many times; and as another power grid, maybe it won't happen again at a time. In that case, even if you can establish all the accident chain model, and how much does it mean? Therefore, the author believes that the research of self-healing recovery should be based on the actual experience of power dispatching and handling accidents, in the research, we must consider the operation mode of the power system in advance, must consider the distribution of the system power flow, we must consider the relay protection equipment and the action of the system, away from these three points, the other analysis is unrealistic. In the course of the study, the focus should be on the development of the "expert system" to be more meaningful. Expert handling systems may not be as rigorous as mathematical models, however, it can simplify complex problems, make the abstract problem more specific, and solve the problem more subtly.

From the domestic and foreign experts and scholars in the study of more than ten years of the self-healing systems can be seen, the self-healing system has indeed very deep side. However, Beijing Jiaotong University Dr. Zhang hao said: "from the perspective of the meaning of the self-healing function and the technical content, it is not a new concept. We previously used to familiar with the relay protection and safety automatic device, belongs to the category of the self-healing function. The self-healing is also the development of the traditional relay protection and safety automatic device technology, its ultimate aim is to provide the uninterrupted ideal power for users, its content is more rich and perfect [28]."

Dr. Zhang Hao also pointed out in his thesis: "intelligent distribution network self-healing control is covering the relay protection, automatic control, applied mathematics, computer and software in the areas of a variety of new technologies and achievements, it is a kind of comprehensive control technology, its basic composition includes the software system with the algorithm as its core, the network framework with the core of a strong flexible physical structure, the intelligent device with the core of reliable distributed hardware, the command scheduling mechanism with the core of information standards [28]." Dr. Zhang Hao's view is, in fact, points out the foothold and starting point of the self-healing system of study to us. To study the self-healing recovery control technology, the network architecture is the premise, accurate and reliable relay protection is the guarantee, a large number of rich real-time data information is condition, and the computer control software of technology advanced is indispensable tools for analysis and making decision. Only for these information resources comprehensive utilization, the self-healing recovery control technology can be obvious onstage.

It is worth mentioning that relay protection in the past 
were a discrete relay, and now has developed into a microcomputer integrated protection relay, but this relay often only set an export contact of the protection action to jump circuit breaker, to reflect the fault types are not clear enough. Because of the clear protection action signal and the circuit breaker tripping accident signal is analysis and judgment the important basis of the scope and points of the accident. Therefore, this kind of defect to be further improved. Now the SCADA data collection and comprehensive monitoring system have or implement the remote communication, telemetry, remote adjustment and remote control functions, however, the false alarm rate of the signal is too high. Because the false alarm signal long-term in the power grid dispatching and operation maintenance personnel's thoughts produced the serious paralysis consciousness, once the serious accident signal comes, will lose a vigilance, even have a distrust on SCADA system. As a result, the system also needs to improve and enhance. But more important is comprehensive in-depth to make the study and development of the self-healing recovery control software, This is also the author has been focused on the research direction. After all, the study of the self-healing recovery control is a huge system engineering, how to study will avoid detours, it is worth many scholars and experts have thought.

The author thinks that, the self-healing recovery control study should be combined with SCADA system and intelligent expert processing system, in the improvement accurate and reliable basis of SCADA system for data acquisition and signal transmitting, in-depth study and development of intelligent expert processing system, and in the process of study and development to handle different types of accident as the main basis, to quickly recovery of power supply as the main goal. Only in this way, developed self-healing recovery control technology will have a real market value.

\section{Conclusion}

The research on self-healing system in smart grid is a worldwide difficult problem, though many scholars and experts have made a lot of efforts, they have not made substantial progress. On the one hand, it is the direction of the study into a misunderstanding, on the other hand, the study process has encountered abottleneck problem indeed. As long as a clear study direction, find the foothold of the study, the intelligent expert processing system study as the breakthrough point, the bottleneck problems will be smoothly done or easily solved. As long as the train of thought and direction for the study, the study of the self-healing system will soon see the hope.

\section{References}

[1] LU Weixing, SHU Yingbiao, et al. WSCC Disturbance on August 10, 1996 in the United States [J]. Power System Technology, 1996, 20 (9): 40-42.
[2] XU Yongxi. Big Blackout in U. S. and Canada August 14, 2003 [J]. International Electric power for China, 2003, 7 (5):15 - 19 .

[3] CHEN-Ching Liu,uhWan Jung,Heydt G T., et al. The Strategic Power Infrastructure Defense (SPID) System. A Conceptual Design [J]. IEEE Control System Magazine, 2000,20 (4): 40-50.

[4] WAN Qiulan. Theory Study for Self-healing of Large Power Grid [J]. Automation of Electric Power Systems, 2009, 33 (17): 29-32.

[5] Notforeve. (Baiding). Self-healing [OL]. (2013). http://baike. so. com/doc/6130009. html.

[6] DONG Xuzhu. Introduction of Self-healing Control Technology in Smart Distribution Systems and Its Application [J]. Southern Power System Technology, 2013, 7 (3): 1-6.

[7] LIU Liangrong. Smart Meter Reading System Design and Implementation [D]. Chengdu:University of Electronic Science and Technology of China, 2013.

[8] CHEN Jingchao. Legislative Research on Renewable Energy in Our Country [D]. Nanjing: Hohai University, 2005.

[9] ChEN lijuan, ZHU Xiaoyan, et al. Survey of Power Grid Real-time Data Integration in China [J]. Electric Power Automation Equipment, 2010, 30 (1): 139-144.

[10] QIN Hongxia, TAN Zhihai, GE Liang, ZHAO Fengqing, et al. Study and Design of Smart Distribution Grid Self-healing Control System Technology [J]. Power System Protection and Control, 2014, 42 (22): 134-139.

[11] LIU Bei, et al. A Phased Fault Restoration Algorithm for distribution System [J]. Power System Protection and Control, 2014, 42 (3): 24 -30.

[12] YU Shibin,XU Bing, et al. Review on Self-healing Control Technique in Smart Distribution Grid [J]. Proceedings of the CSU-EPSA, 2013, 25 (5): 65-70.

[13] CHEN Anwei. Research on the Technical Economic Problems of the Smart Grid [D]. Chongqing: Chongqing University, 2012.

[14] LI Bing, HAN Tianbo, et al. Protection Research of the Distribution Network with Photovoltaic Power [J]. Mechanical \& Electrical Engineering Technology, 2013, 42 (12): 46-49.

[15] ZHANG Wenliang, LIU Zhuangzhi, WANG Mingjun, et al. Research Status and Development Trend of Smart Grid [J]. Power System Technology, 2009, 33 (13): 1-11.

[16] WANG Chengshan, NIE Song, et al. Analysis on the Impact of DG on Distribution Network Reconfiguration [J]. Journal of Tianjin University (Science and Technology), 2014, 47 (3): 189-194.

[17] JIA DongLi, MENG XiaoLi, SONG XiaoHui. Study on Technology System of Self-healing Control in Smart Ddistribution Grid [c]. 2011 The International Conference on Advanced Power System Automation and Protection. Volume: 1, Publication Year: 2011, Page (s): 26 - 30.

[18] GUO Zhizhong. Seheme of Self-healing Control Frame of Power Grid [J]. Automation of Electric Power Systems, 2005, 29 (10): 85-91. 
[19] YU Kun. Study on Self-healing Control of the Urban Power Grid Based on Hierarchical Control Theory [D]. Hangzhou: Zhejiang University, 2011.

[20] ZHENG Xiaofan, JIAO Feng. Smart Grid Self-healing Control Based on Power Immune System [J]. China Electric Power (Technology Edition), 2012, 1: 25-28.

[21] DONG Xuzhu, HUANG Shaoyuan,CHEN Rouyi, et al. Self-healing Control Technology for Smart Distribution System [J]. Automation of Electric Power Systems, 2012, 35 (18): 16-21.

[22] ZHANG Mingguang, LU Yunyun. A Self-healing of Smart Distribution Control Based on Multi-agent System [J]. Power Supply Technology and Its Application, 2012, 38 (11): 77-83.

[23] HONG Tao. Analysis of Present Situation and Development of Smart Distribution Network Fault Restoration [J]. Silicon Valley, 2014, 166 (22): 177-178.
[24] YUAN Bo, WANG Ying. Self-healing Control and Its Key Technology in Smart Distribution Grid [J]. Electrotechnics Electric, 2014, 8: 1-5.

[25] SHENG Bingbing, WU Lin, WANG Peng, et al. Technological Characteristics and Application Effects Analysis of Distribution Automation Pilot Projects [J]. Automation of Electric Power Systems, 2012, 36 (18) : 27-32.

[26] YAN Lei, CHANG Haijiao, et al. Discussions on the Situations and Development Trends of Medium Voltage Power Line Carrier Communication [J]. Electric Power Information and Communication Technology, 2014, 12 (1): 16.

[27] LUO Jinshan, LUO Yi, TU Guangyu. Study on Fault Chains Monitoring in Regional Power Network by Using a Stochasitic Petrinet Model [J]. Relay, 2006, 34 (7): 32-37.

[28] ZHANG Hao. Collaborative Protection and Self-healing Control for Distribution Networks [D]. Beijing: Beijing Jiaotong University, 2010. 